\title{
Terbinafine-induced subacute cutaneous lupus erythematosus in two patients with systemic lupus erythematosus successfully treated with topical corticosteroids
}

\author{
Agnieszka Kalińska-Bienias, Cezary Kowalewski, Katarzyna Woźniak
}

Department of Dermatology and Immunodermatology, Medical University of Warsaw, Poland Head: Prof. Cezary Kowalewski MD, PhD

Postep Derm Alergol 2013; XXX, 4: 261-264

DOI: 10.5114/pdia.2013.37038

\begin{abstract}
So far in the literature there have been reported only 5 patients with a recognized and well-documented history of systemic lupus erythematosus (SLE) who developed SCLE after terbinafine introduction. Here we report two women suffering from SLE who developed SCLE after initiation of oral terbinafine for onychomycosis. Skin lesions in both of them were extensive, located on the trunk, and upper and lower extremities. No exacerbation of SLE symptoms was observed at that time. Despite severe skin lesions, patients revealed good response to topical corticosteroids within a few weeks. The systemic review of the literature and our experience on terbinafine-induced SCLE developing in patients with SLE allowed to create a description for this special subset: a) terbinafine-induced SCLE usually develop in 1-8 weeks after terbinafine introduction, b) skin lesions are usually severe, disseminated including lower extremities, c) patients present Ro/SS-A La/SS-B antibodies, but anti-histone antibodies are rarely observed, d) exacerbation of SLE symptoms is rather not observed, e) eruptions clear within 2-8 weeks, f) withdrawal of terbinafine and topical corticosteroids should be considered as a first-line therapy in these cases, g) terbinafine should be carefully used in patients suffering from SLE.
\end{abstract}

Key words: terbinafine-induced subacute cutaneous lupus erythematosus, terbinafine.

\section{Introduction}

Drug-induced lupus erythematosus (DI-LE) is diagnosed when clinical and immunopathological symptoms are similar to idiopathic lupus in patients with no prior history of lupus and are related to drugs [1]. A characteristic feature of the DI-LE is the resolution of symptoms after discontinuation of the offending drug and relapse after re-exposure. Similar to idiopathic lupus, DI-LE can be divided into systemic (DI-SLE), subacute cutaneous (DI-SCLE) and discoid lupus erythematosus (DI-DLE). It is estimated that the incidence of drug-induced LE represents about $10 \%$ of cases identified as LE. The list of drugs provoking LE includes over 80 different chemical compounds [1].

The first case of drug-induced SLE was described in 1945 [2]. The triggering factor was sulfadiazine administered in the treatment of arterial hypertension. Since that time, there have been many reported cases of patients with druginduced LE. Amongst the most commonly known drugs that provoke DI-SLE are hydralazine, procainamide, quinidine, isoniazid and recently reported tumor necrosis factorantagonists [1].

The pathomechanism of DI-LE still remains unclear. There is evidence that some genetic factors such as antigens HLA DR: HLA DR2, HLA DR3, HLA DR4 type are associated with DI-LE and also the speed of the reaction of acetylation, which is a feature determined genetically. The slow acetylators are observed to have an increase in the production of autoantibodies and more frequent development of DI-LE [3]. It is also suggested that the drug or its metabolites may bind to proteins that become foreign and then initiate an immune response against hapten or autoantigens by molecular mimicry [4]. Other authors consider that

Address for correspondence: Agnieszka Kalińska-Bienias MD, Department of Dermatology, and Immunodermatology, Medical University of Warsaw, 82 A Koszykowa St, $02-008$ Warsaw, Poland, phone: +48 606618 564, e-mail: agnieszka.kalinska@interia.pl Received: 3.04.2013, accepted: 23.06.2013. 


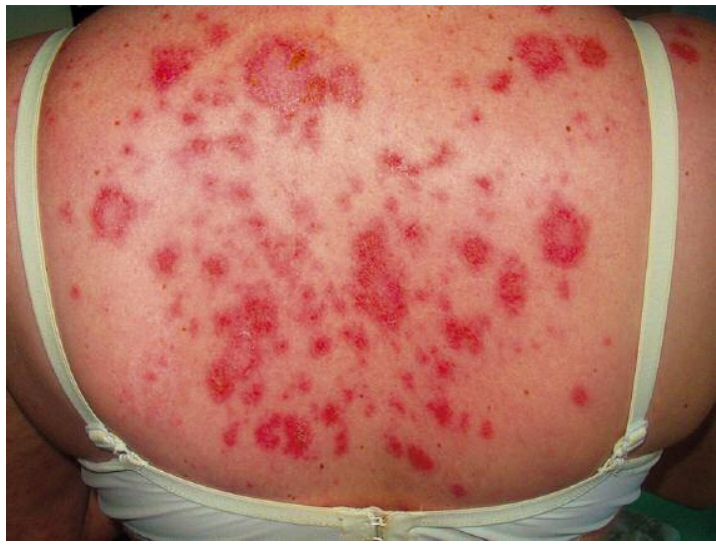

Fig. 1. Annular lesions with central regression and little scaling on the edge of the lesion located on the trunk (patient 1)

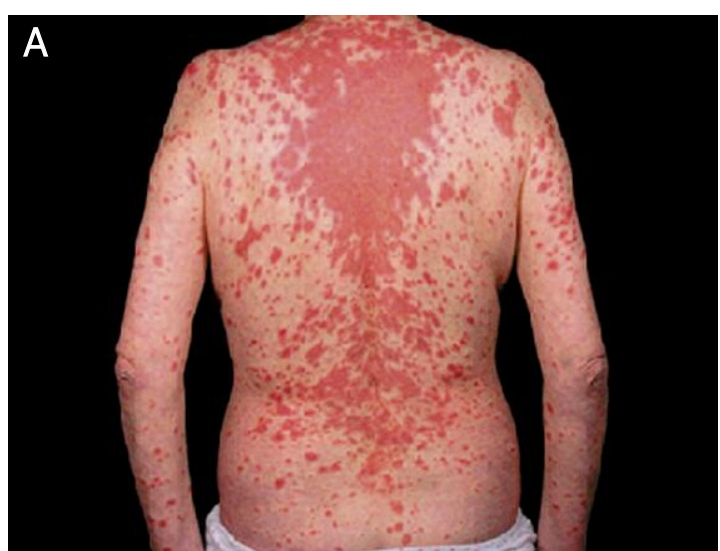

B

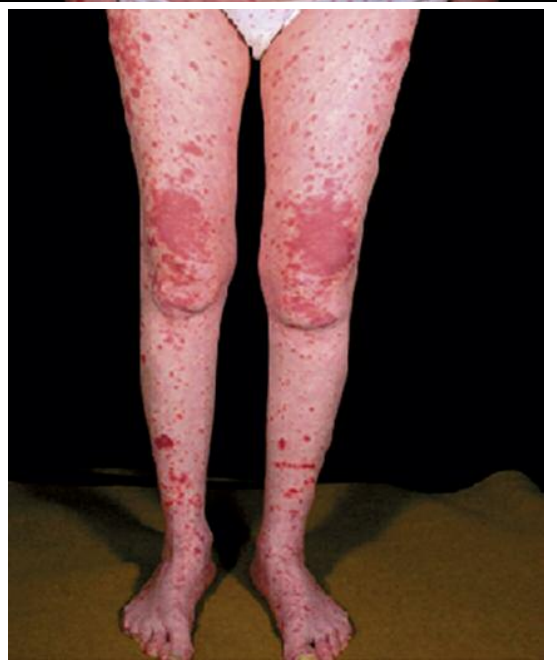

Fig. 2 A-B. Extensive erythematous well-demarcated plaques located on the trunk and the upper and lower extremities (patient 2)

the metabolites of drugs can cause apoptosis in the way of a non-immune-mediated process of direct cytotoxicity. It is also hypothesized that function of T-cells is altered by hypomethylation of DNA, making the T-cell autoreactive and promoting their activation [3].
Drug-induced subacute cutaneous lupus (DI-SCLE) was described for the first time by Reed et al. in 1985. The authors reported 5 patients without previous symptoms of lupus erythematosus, in which the clinical, histopathological and immunological (anti-Ro/SS-A, anti-La/SS-B) symptoms typical of the SCLE developed after starting hydrochlorothiazide [5]. Subsequently, a variety of drugs, including terbinafine, were reported to be responsible for DI-SCLE. Terbinafine being an oral allylamine antifungal drug is widely used by dermatologists because of a large spectrum of action for dermatophytes. On the other hand, this drug may be responsible for a variety of commonly observed skin side effects, i.e. nonspecific skin rash, urticaria, papulopustular eruptions, hyperpigmentations as well as more severe disorders like erythema multiforme, Stevens-Johnson syndrome, toxic epidermal necrolysis, acute generalized exanthematous pustulosis and SCLE [6].

The first case of terbinafine-induced SCLE without a history of SLE was described in 1998 [7]. Since that time another 31 cases have been published, representing $26 \%$ of all cases of DI-SCLE [6, 8-10]. The pathomechanism of terbinafine-induced SCLE has not been understood so far. However, it is postulated that terbinafine with its lipophilic and keratophilic properties may change the configuration of nuclear antigens and induce antinuclear antibodies (ANA) formation [11]. Terbinafine may also be involved in enhancing the cytotoxic reaction dependent on anti-Ro antibodies and keratinocyte damage typical of SCLE [12].

In this article we report two women with a many years' history of SLE who developed SCLE after administering terbinafine.

\section{Case reports}

\section{Case 1}

A 43-year-old patient developed SLE at the age of 24. The symptoms of the disease included central nervous system involvement (paranoid schizophrenia), kidney involvement, Raynaud's phenomenon, arthralgia, vascular lesions on the fingertips of the hands and feet, and pancytopenia. The indirect immunofluorescence study revealed antinuclear antibodies in a titer of $1: 640$, Ro+/SS-A, La+/SS-B. During the course of the disease the patient occasionally presented butterfly rash on the face. SLE was controlled with methylprednisolone, $4 \mathrm{mg}$ daily. When admitted to the Department of Dermatology, the patient presented annular skin lesions resembling SCLE, located mainly on the upper part of the body (Figure 1). Skin lesions occurred after 8 weeks of introducing terbinafine at a dose of $250 \mathrm{mg}$ daily due to onychomycosis of the toe nails. Indirect immunofluorescence (IIF) revealed antinuclear antibodies in a titer of $1: 40$, Ro/SS-A. Additional studies demonstrated no increase in severity of SLE symptoms. Terbinafine was discontinued. The treatment of methylprednisolone of $4 \mathrm{mg}$ daily was continued and accom- 
Table 1. Characteristics of cases with SLE who developed terbinafine-induced SCLE

\begin{tabular}{|c|c|c|c|c|c|c|c|}
\hline Authors & $\begin{array}{c}\text { Gender/ } \\
\text { age }\end{array}$ & $\begin{array}{l}\text { Duration } \\
\text { of SLE } \\
\text { [years] }\end{array}$ & $\begin{array}{l}\text { Time of skin } \\
\text { development } \\
\text { after terbinafine } \\
\text { introduction } \\
\text { [weeks] }\end{array}$ & $\begin{array}{l}\text { Skin lesion } \\
\text { resolution } \\
\text { time } \\
\text { [weeks] }\end{array}$ & Serology & $\begin{array}{l}\text { Treatment } \\
\text { of SLE }\end{array}$ & $\begin{array}{l}\text { Treatment of } \\
\text { terbinafine-induced } \\
\text { SCLE }\end{array}$ \\
\hline $\begin{array}{l}\text { Cetkovska } \\
\text { et al. [14] }\end{array}$ & $F / 39$ & 10 & 1 & Few & $\begin{array}{l}\text { Ro/SS-A, } \\
\text { La/SS-B, } \\
\text { ds-DNA }\end{array}$ & $\begin{array}{l}\text { MP } 8 \mathrm{mg} / \text { day, } \\
\text { A } 50 \mathrm{mg} / \text { day }\end{array}$ & $\begin{array}{c}\text { MP 64-100 mg/day } \\
\text { CyA } 4 \text { mg/kg/day } \\
\text { MM } 2 \text { g/day }\end{array}$ \\
\hline $\begin{array}{l}\text { Callen } \\
\text { et al. [13] }\end{array}$ & $M / 51$ & 10 & 8 & 6 & $\begin{array}{l}\text { Ro/SS-A, } \\
\text { La/SS-B, } \\
\text { ds-DNA }\end{array}$ & P 20 mg/day & D $50 \mathrm{mg}$ \\
\hline $\begin{array}{l}\text { Callen } \\
\text { et al. [13] }\end{array}$ & $M / 50$ & 22 & 4 & 8 & $\begin{array}{l}\text { Ro/SS-A, } \\
\text { La/SS-B, } \\
\text { ds-DNA }\end{array}$ & A & P $40 \mathrm{mg}$ \\
\hline $\begin{array}{l}\text { Callen } \\
\text { et al. [13] }\end{array}$ & $F / 41$ & 3 & 4 & 8 & $\begin{array}{l}\text { Ro/SS-A, } \\
\text { La/SS-B }\end{array}$ & $\mathrm{HCl}$ & $\begin{array}{c}\mathrm{P}, \\
\mathrm{HCl}, \\
\text { topical clobetasol }\end{array}$ \\
\hline $\begin{array}{l}\text { Holmes } \\
\text { et al. [15] }\end{array}$ & $F / 59$ & 1 & 4 & 3 & $\begin{array}{l}\text { Ro/SS-A, } \\
\text { ds-DNA }\end{array}$ & None & $\begin{array}{l}\text { P } 30 \mathrm{mg} / \text { day, } \\
\text { topical steroids }\end{array}$ \\
\hline $\begin{array}{l}\text { Reported } \\
\text { case }\end{array}$ & $F / 43$ & 19 & 8 & 2 & $\begin{array}{l}\text { Ro/SS-A, } \\
\text { La/SS-B }\end{array}$ & MP 4 mg/day & $\begin{array}{c}\text { Topical } \\
\text { mometasone }\end{array}$ \\
\hline $\begin{array}{l}\text { Reported } \\
\text { case }\end{array}$ & $F / 53$ & 16 & 3 & 2 & $\begin{array}{l}\text { Ro/SS-A, } \\
\text { La/SS-B }\end{array}$ & MP 12 mg/day & $\begin{array}{c}\text { Topical } \\
\text { hydrocortisone }\end{array}$ \\
\hline
\end{tabular}

F-female, M-male, MP-methylprednisolone, $P$ - prednisone, $A$ - azathioprine, CyA - cyclosporine A, MM-mycophenolate mofetil,

$\mathrm{D}$-dapson, $\mathrm{HCl}$ - hydroxychloroquine

panied by topical furoate mometasone leading to lesions improvement within 3 weeks.

\section{Case 2}

A 53-year-old patient developed SLE at the age of 37 presenting severe arthralgia, myalgia, and Raynaud's phenomenon, butter-fly erythema on the face and erythema on the dorsum of her hands, leukopenia, and hypersensitivity to UV. Indirect immunofluorescence disclosed ANA in a titer of $1: 1280$, characterized by Ro/SS-A and La/SS-B types. For several years the disease was under control while she was taking only methylprednisolone at a dose of $12 \mathrm{mg}$ daily. The patient was admitted to the Department of Dermatology because of severe erythematous lesions forming annular arrangement located on the trunk and the upper and lower limbs (Figures 2 A-B), typical for SCLE. Skin lesions occurred after 3 weeks of administering terbinafine at a dose of $250 \mathrm{mg}$ daily due to nail tinea. During hospitalization additional studies found no exacerbation of SLE symptoms. In a study of the IIF antinuclear antibodies in a titer of 1 : 40 was detected, Ro/SS-A. Terbinafine was discontinued 3 days before admission. Because of severity of skin lesions the dose of methylprednisolone was increased to $24 \mathrm{mg}$ daily and 1\% hydrocortisone ointment was added. After 2 weeks the skin lesions significantly improved and methylpred- nisolone was reduced. Skin lesions cleared within the next 2 weeks on topical corticosteroids.

\section{Discussion}

In this article two new cases of terbinafine-induced SCLE in patients with a history of many years' SLE are reported. So far, only 5 such cases have been described in the English language literature (Table 1). The average age of patients with SLE and terbinafine-induced SCLE was 48 years (range: $39-59$ years) [13-15]. The age of both our patients fitted the previously described range, being 43 and 53 years respectively. In previously published cases skin lesions developed in 1 to 8 weeks after terbinafine had been introduced. All of them presented disseminated eruptions located on the trunk and upper and lower extremities [13-15]. Our patients presented similar clinical features which developed 3 and 8 weeks after receiving terbinafine.

The DI-SCLE does not differ from the idiopathic SCLE in the clinical, pathological, immunological and laboratory abnormalities, but differs from DI-SLE. Drug-induced SLE is characterized by fever, arthritis and serositis, renal changes, neurological symptoms or pancytopenia, whereas skin symptoms are observed only in one third of DI-SLE patients, the most common are purpura or urticarial vasculitis [1]. Our patients fulfilled none of the above-mentioned symptoms, what rather supports the diagnosis of DI-SCLE, 
and not DI-SLE in them. Similarly to our patients, cases described previously did not show these symptoms either [13-15]. Moreover, in contrast to DI-SLE, DI-SCLE patients often develop skin lesions located on lower limbs, which is probably a systemic effect of the offending drug [10]. This was observed in previously and both presently published cases [13-15].

The immunologic profile of published cases is comparable to that of our patients [13-15]. All of them had Ro/ SS-A and La/SS-B antibodies before SCLE developed and persisted despite skin eruptions had cleared. Although anti-histone antibodies serve as a marker for drug-induced LE they are detectable only in about 30\% [10]. Anti-histone antibodies were observed in only 1 out of 5 published cases with SLE and coexisting terbinafine-induced SCLE [13-15].

Interestingly, all published cases were taking only maintenance treatment for SLE at the time they were administered terbinafine [13-15]. Despite the fact that in none of them SLE symptoms exacerbated, all received systemic treatment (prednisone, disulone, mycophenolate mofetil, cyclosporine A), which is not indifferent to patients with SLE who have a long-lasting history of immunosuppressive therapy and usually many associated complications [16]. Our patients achieved remission of skin lesions within a few weeks as a result of topical corticosteroids treatment. In general, according to the literature, the majority of cases of DI-SCLE (not related to the SLE) either resolved spontaneously with no treatment or the treatment had no effect on the rate of DI-SCLE resolution and this lasted 6 weeks on average [10]. Therefore, we propose topical corticosteroids as a first-line therapy to avoid side effects related to systemic immunosuppressants in such cases.

The systemic review of the literature and our experience on terbinafine-induced SCLE developing in patients with SLE allows to create the following description for this special subset: a) terbinafine-induced SCLE usually develop in 1-8 weeks after terbinafine introduction, b) skin lesions are usually severe, disseminated including lower extremities, c) patients present Ro/SS-A, La/SS-B antibodies, but antihistone antibodies are rarely observed, d) exacerbation of SLE symptoms is not observed, e) eruptions clear within 2-8 weeks, f) withdrawal of terbinafine and topical corticosteroids should be considered as a first-line therapy in these cases, g) terbinafine should be contraindicated in patients suffering from SLE. We hope that above-mentioned characteristics will be helpful in managing of cases with terbinafine-induced SCLE developed in patients with SLE.

\section{References}

1. Marzano AV, Vezzoli P, Crosti C. Drug-induced lupus: an update on its dermatologic aspects. Lupus 2009; 18: 935-40.

2. Hoffman BJ. Sensitivity to sulfadiazine resembling acute disseminated lupus erythematosus. Arch Derm Syphilol 1945; 51: 190-2.

3. Vedove CD, del Giglio M, Schena D, et al. Drug-induced lupus erythematosus. Arch Dermatol Res 2009; 301: 99-105.
4. Griem P, Wulfering M, Sachs B, et al. Allergic and autoimmune reactions to xenobiotics: how do they arise? Immunol Today 1998; 19: 133-41.

5. Reed BR, Huff JC, Jones SK, et al. Subacute cutaneous lupus erythematosus associated with hydrochlorothiazide therapy. Ann Intern Med 1985; 103: 49-51.

6. Lorentz K, Booken N, Goerdt S, et al. Subacute cutaneous lupus erythematosus induced by terbinafine: case report and review of literature. J Dtsch Dermatol Ges 2008; 6: 823-8.

7. Murphy M, Barnes L. Terbinafine-induced lupus erythematosus. Br J Dermatol 1998; 138: 708-9.

8. Hivnor CM, Hudkins ML, Bonner B. Terbinafine-induced subacute cutaneous lupus erythematosus. Cutis 2008; 81: 156-7.

9. Kasperkiewicz M, Anemüller W, Angelova-Fischer I, et al. Subacute cutaneous lupus erythematosus associated with terbinafine. Clin Exp Dermatol 2009; 34: 403-4.

10. Lowe G, Henderson CL, Grau RH, et al. A systematic review of drug-induced subacute cutaneous lupus erythematosus. Br J Dermatol 2011; 164: 465-72.

11. Bonsmann G, Schiller M, Luger TA, et al. Terbinafine-induced subacute cutaneous lupus erythematosus. J Am Acad Dermatol 2001; 44: 925-31.

12. Furukawa F, Itoh T, Wakita H, et al. Keratinocytes from patients with lupus erythematosus show enhanced cytotoxicity to ultraviolet radiation and to antibody-mediated cytotoxicity. Clin Exp Immunol 1999; 118: 164-70.

13. Callen JP, Hughes AP, Kulp-Shorten C. Subacute cutaneous lupus erythematosus induced or exacerbated by terbinafine: a report of 5 cases. Arch Dermatol 2001; 137: 1196-8.

14. Cetkovska P, Pizinger K. Coexisting subacute and systemic lupus erythematosus after terbinafine administration: successful treatment with mycophenolate mofetil. Int J Dermatol 2006; 45: 320-2.

15. Holmes S, Kemmett D. Exacerbation of systemic lupus erythematosus induced by terbinafine. Br J Dermatol 1998; 139: 1133.

16. Samborski W. Pharmacological treatment of lupus erythematosus systemicus: new directions including experimental methods. Postep Derm Alerg 2004; 21: 30-5. 